\title{
A ETNOMUSICOLOGIA SOB UM OLHAR CONTEMPORÂNEO
}

\section{LA ETNOMUSICOLOGÍA EN UNA MIRADA CONTEMPORÁNEA}

THE ETHNOMUSICOLOGY UNDER A CONTEMPORARY LOOK

\author{
Jonathan Lambert SILVA ${ }^{1}$
}

RESUMO: O presente artigo tem por objetivo fazer uma discussão sobre o desenvolvimento da área da etnomusicologia através de trabalhos como o de Tiago de Oliveira Pinto e Rafael José de Menezes Bastos tendo em vista o olhar antropológico que permeia as discussões contemporâneas sobre sistema global e cultura local.

PALAVRAS-CHAVE: Etnomusicologia. Cosmologias. Cultura contemporânea.

RESUMEN: Lo presente artículo tiene por finalidad hacer una discusión sobre el desarrollo del área de la etnomusicología a través de trabajos como el de Tiago de Oliveira Pinto y Rafael José de Menezes Bastos teniendo em vista la mirada antropológica que permea las discusiones contemporáneas acerca del sistema global y de la cultura local.

PALABRAS CLAVE: Etnomusicología. Cosmologías. Cultura contemporánea.

ABSTRACT: The present article aims to discuss the development of the ethnomusicology area through works of Tiago de Oliveira Pinto and Rafael José de Menezes Bastos focusing the anthropologic look that permeate the contemporary discussions about the global system and the local culture.

KEYWORDS: Ethnomusicology. Cosmologies. Contemporary culture.

\section{Introdução}

Em uma discussão feita sobre a abrangência da disciplina da etnomusicologia, Rafael José de Menezes Bastos e Tiago de Oliveira Pinto fazem um extenso levantamento sobre o que tem constituído as discussões e metodologias utilizadas pela área em sua atuação em meio à pesquisa das mais diversas formas de musicalidade.

${ }^{1}$ Universidade Estadual Paulista (UNESP), Araraquara - SP - Brasil. Graduando em Ciências Sociais. ORCID: <https://orcid.org/0000-0002-2561-029X>. E-mail: jonathan.lambert.silva@gmail.com 
No desenvolvimento histórico da etnomusicologia, a tese de Bastos contribui com um dilema: os estudos musicológicos em seu início focalizavam o estudo da música enquanto fenômeno acústico, sonoro e, portanto, deixavam de lado ou mesmo negligenciavam o aspecto contextual e cultural por trás da música, o que acabou por afetar mesmo a sua condição semântica.

Nesse sentido, o presente artigo busca discutir o trajeto da disciplina e mesmo algumas questões trazidas pelos dois autores à luz de autores como Marshall Sahlins e Clifford Geertz, para tentar dar uma nova perspectiva ao problema e trazer algumas questões contemporâneas acerca do choque entre cultura local e global que tem se estabelecido no contato entre as áreas da Musicologia e da Antropologia.

\section{Etnomusicologia como área de pesquisa}

A etnomusicologia em uma primeira definição feita por Adler (1885 apud BASTOS, 2014, p. 53) teria como tarefa "comparar a produção tonal, especialmente os cânticos folclóricos dos diferentes povos, países e territórios, com propósito etnográfico" de modo que então estas pudessem ser classificadas conforme suas propriedades. Note-se que no tocante a essa classificação ela seria ao mesmo tempo uma antropologia e uma musicologia, em que o objeto que estaria em jogo para a classificação seriam "os discursos voco-sonoros humanos" (BASTOS, 2014, p. 54) em sua concretude material-sonora.

Já para Jaap Kunst (1950 apud BASTOS, p. 54-55), a área estuda "a música e os instrumentos musicais de todos os povos não-europeus, incluindo tanto os chamados povos primitivos quanto as nações civilizadas orientais", onde os cantos folclóricos são elementos marginais que dão lugar à música e aos instrumentos musicais não-europeus. É com ele que o que é tido como música primitiva vai ganhando maior espaço como objeto de estudo da etnomusicologia, passando a deixar de lado a Música Ocidental enquanto objeto de estudo.

Com Béla Bartók e seus estudos sobre o folclore musical húngaro, a discussão sobre o que é o objeto da disciplina ganha novas proporções, na medida em que ao considerar as músicas folclóricas como tão 'estranhas' como as músicas primitivas e exóticas, elas entravam como novos objetos da etnomusicologia não só por seu elemento estético, mas também por conta de seu caráter político, visto que ao reconhecê-la dentro da universalidade da Música Ocidental, elas seriam elementos que conformariam uma identidade cultural tão legítima como a de outras sociedades como a francesas e a alemã, por exemplo (BASTOS, 2014, p. 57). Semelhante ao que Pinto (2001, p. 261-262) defende, dado que para ele, a preservação da 
música tradicional se dá pela possibilidade de afirmação e da construção de uma identidade cultural nacional canalizada por meio da música, na qual os governos passam a atuar com medidas de preservação do patrimônio imaterial nacional. Esse é um movimento que o próprio Bastos (2014, p. 58) vai colocar como responsável por uma 'outrificação' do 'nós' e familiarização de alguns 'outros'.

Outro esforço de desenvolvimento em meio a disciplina será realizado na Escola de Berlim de Musicologia Comparada, com a união de Erich von Hornbostel e Curt Sachs, motivada por um estudo transcultural dos "processos mentais envolvidos na música, especificamente se interessando pela análise melódica e organológica” (BASTOS, 2014, p. 58). Hornbostel e Sachs, ligados ao Instituto de Psicologia da Universidade de Berlim, baseiam-se numa abordagem difusionista. Influenciados também pelas ideias evolucionistas postulavam uma unidade psíquica da humanidade em que os povos primitivos se estabeleciam em estágios anteriores de evolução aos povos europeus, em conformidade com o panorama antropológico que havia na época no início do século XX. Ainda assim, os dois foram responsáveis pela elaboração de uma sistemática dos instrumentos musicais que, segundo Pinto (2001, p. 271), é uma das obras mais consistentes e citadas de etnomusicologia.

A expansão da área da Musicologia Comparada na Alemanha durante o início do século XX culminou na criação da Gesellschaft zur Erforschung der Musik des Orients em 1930 que mais tarde em 1933 se tornou a Gesellschaft für Vergleichende Musikwissenschaft. Porém, com a ascensão do nazismo, no mesmo ano foi criada a American Society for Comparative Musicology, como organização oriunda da alemã, onde o aluno de Hornbostel, Herzog, participava do Comitê Organizador e da primeira diretoria. Herzog no ano anterior, 1932, havia se mudado para os EUA devido às tensões com o regime em ascensão em seu país, indo estudar com Franz Boas na Universidade de Columbia, levando consigo os fonogramas do Arquivo alemão do Instituto de Psicologia (BASTOS, 2014, p. 60).

A etnomusicologia que ia surgindo nos Estados Unidos por influência de Boas, diferente do que na Alemanha que se ligava à área da Psicologia, lá passava a se conectar mais profundamente com a área da Etnologia. Basta lembrar que segundo Bastos (Ibid., p. 61), Boas foi professor de Alfred Louis Kroeber e de Melville Jean Herskovits, professores por sua vez de Helen Heffron Roberts e de Alan Parkhurst Merriam, ambos importantes quadros do estudo etnomusicológico nos EUA. Se com Nettl, aluno de Herzog, que em 1956 escreve o primeiro manual da área nomeado Music in Primitive Culture, no qual entendia que a disciplina deveria estudar três tipos de música: oriental, folclórica e primitiva (todos também parte dos campos de estudo da Antropologia de então), um pouco depois, Merriam, foi responsável pela formulação 
de uma teoria etnomusicológica, que tinha por necessidade a incorporação de metodologias de pesquisa provindas tanto da musicologia quanto da antropologia.

Música é definida por Merriam como um meio de interação social, produzida por especialistas (produtores) para outras pessoas (receptores); o fazer musical é um comportamento aprendido, através do qual sons são organizados, possibilitando uma forma simbólica de comunicação na interrelação entre indivíduo e grupo [...] (PINTO, 2001, p. 224).

A questão abordada tanto por Bastos quanto por Pinto é a de que houve um momento em que o estudo etnomusicológico deixou de se aportar apenas em entender os fenômenos acústicos provindos dos sons, para buscar entender as diferentes formas de música, por meio da adoção progressiva de ferramentas metodológicas da pesquisa etnográfica. Esse esforço dá grandes passos com Merriam por deixar de partir de uma concepção que propõe estudar a música na cultura para começar a estudá-la como forma de cultura. O ponto em questão aqui é o que Bastos busca trabalhar em todo seu artigo, na medida em que ele vê que o dilema etnomusicológico acabava reduzindo a expressão da música a duas abordagens, uma enquanto som e outra enquanto comportamento. Isto, por sua vez, produzia uma 'antropologia sem música' e uma 'musicologia sem homem', gerando então uma negação da semanticidade da música, pois ela entendida apenas enquanto produto que cabe aos sentidos, era esvaziada de seu conteúdo e de seu sentido. Portanto, seria tarefa da etnomusicologia fazer um adequado equacionamento que passasse a considerar o contexto cultural como um todo para a compreensão do fenômeno musical.

\section{Dificuldades e obstáculos na etnomusicologia}

Desde os seus primeiros passos enquanto disciplina, a etnomusicologia se deparava com algumas problemáticas, uma delas é que sua primeira fase foi marcada por um interesse de preservação de tradições musicais inteiras, dado o receio de que houvesse o desaparecimento completo dessas formas de expressão musicais tradicionais. Foi por conta desse receio que nos primeiros momentos o problema que se colocava consistia em "como descrever e fixar no papel, ou de outra forma visual, o acontecimento musical", no qual "pesquisadores de tradições 'exóticas' apresentavam as músicas transcritas em pauta na qualidade de documentos" (PINTO, 2001, p. 257).

É importante salientar que um importante momento para a metodologia de pesquisa na área, que permitiu superar o problema da transcrição musical, foi o desenvolvimento do 
fonógrafo por Thomas Alva Edison em 1877, possibilitando o registro e a reprodução de sons e músicas. A partir de então nos anos de transição do século XIX ao XX foram criados uma série de Arquivos Fonográficos com o objetivo de preservação desse acervo sonoro-musical, como o de Viena, Berlim, Paris e São Petersburgo.

O que é colocado a todo o momento por Bastos (2014, p. 54-55) em seu levantamento sobre o desenvolvimento da etnomusicologia é um certo olhar de que a cultura primitiva estaria situada nos primórdios do que se entende por cultura Ocidental. Nesse olhar, a música está se calcando em visões e correntes de pensamento relacionadas com o entendimento antropológico da época em questão, tocando em questões como o colonialismo, a construção do Estado Moderno e dos binômios 'nós' e 'outros' e 'civilizado' e 'selvagem'.

A problemática de como se faz o registro desses fenômenos musicais é um bom exemplo desse processo, na medida em que se por um lado Pinto (2001, p. 258) afirma que existe uma série de problemáticas que permeavam a transcrição musical, por ela ser um modo de escrita que diz respeito à história da música Ocidental e que, portanto, seria incompatível com os sistemas musicais não-ocidentais. A problemática que se estabelece aqui gira em torno da questão da tradutibilidade das formas de cultura, dado que a transcrição musical não seria um documento de análise da cultura por ter passado por uma interpretação daquele que a transcreveu, enquanto agente e portador de certo aprofundamento da cultura musical que nem sempre condiz com as concepções nativas acerca da música. Para a solução desse problema, o autor coloca que a transcrição musical não supera de maneira alguma o registro sonoro e audiovisual coletados em campo.

Bastos (2014, p. 56), no tocante a esse ponto, estabelecerá uma relação entre a partitura e o fonógrafo em que este último, como uma espécie de 'congelamento' e conservação do som e da musicalidade de sociedades que não a Ocidental, seria intento de suprimir a distância e de revertê-la em proximidade, mas que no final das contas desembocaria numa 'objetivação da distância' e numa espécie de 'outrificação'. Já a musicologia que tem por objeto de estudo a música Ocidental, por não constituir algo a ser 'outrificado', poderia se utilizar da partitura enquanto elemento gráfico de estudo, ao invés do fonógrafo dado a proximidade de seu objeto.

Outro ponto colocado por Bastos (2014, p. 64) e que resultará nessa fundamentação da relação 'nós' e 'outros', está relacionada ao fato de que no Ocidente o estudo da música enquanto intento em direção à inteligibilidade se choca com o paradoxo de que a própria música ao ser enquadrada como arte consagrou-se no indivíduo (ou mesmo quando no social) como produto da sensibilidade. O social que é buscado pela etnomusicologia, para o autor, se encontra 
no terreno da extrema alteridade, num 'éthne' que de forma alguma se assemelha ao 'nós', mas que estão ligados ao 'outro', aos povos não-ocidentais.

Nessa dinâmica de 'outrificação' e de construção de certo ‘nós' e certo 'outro', há o que Bourdieu (2007) caracteriza como uma lógica de diferenciação na qual a identidade social seria construída num processo de constante classificação do 'outro' e do mundo de modo que nesse processo o agente classificador (no caso da música, aquele portador dos aparatos e conhecimentos técnicos característicos da música Ocidental) também acaba se classificando enquanto diferente daquele a quem se estuda. O que está em causa é um movimento de construção de fronteiras simbólicas que pretende expressar o que une certo grupo e o que o separa de outros grupos e como esse processo ocorre de maneira ainda mais intensa no que tange a separação entre a música Ocidental de um lado e as diversas musicalidades primitivas, exóticas ou folclóricas de outro. Entende-se que o processo de distinção ocorre em decorrência do grupo dominante (aquele mesmo que é o portador da mentalidade colonialista) num discurso que permeava a etnomusicologia e que acabava reforçando certas características que construíam um sujeito 'civilizado' em contraposição a um sujeito 'selvagem',

Portanto, quando Merriam (1966, p. 25 apud BASTOS, 2014, p. 67-68), ao ver que se deveria estudar a música como forma de cultura, ele observa que o objetivo do etnomusicólogo seria o de criar uma ponte entre as humanidades (entendidas por ele como o campo da sensibilidade) e as ciências sociais. Há um entendimento de cultura e música que se faz presente em Merriam nesse momento, cultura seria entendida como "o comportamento humano aprendido e acumulado" (Ibid., p. 68) e música como um produto do homem que é possuidora de uma estrutura que não é cindida de seu comportamento, portanto, da cultura. É com essa transição que pode ser efetivada uma abertura para que se atribua uma verdadeira semanticidade à música.

\section{A Semântica Musical e a Teoria Nativa}

O problema que estava colocado até então pela Etnomusicologia e que tendia a uma negação da semanticidade da música para Bastos era o dilema que se encontrava na área de estudo quando separava a música de seu contexto, recaindo no absurdo de um congelamento da "linguagem musical (minimizada ao som) na sensorialidade pura, desapropriando-a de toda inteligibilidade" (BASTOS, 2014, p. 52). Daí que o problema por trás da semântica musical se situa na possibilidade da evidenciação das transformações inconscientes que ocorrem no nativo 
entre a expressão e o conteúdo, que para Bastos (2014, p. 52 e 71) pode ser solucionado pelo entendimento da música como um sistema significante e de significado pleno, que é um produto social não só por seu conteúdo, bem como também por sua forma.

Se partirmos da concepção de Clifford Geertz (1978) sobre a Cultura como estruturas de significado socialmente estabelecidas que são passíveis de interpretação, sendo eles acontecimentos sociais, comportamentos, instituições e processos, o que está em causa aqui na etnomusicologia é que a música seja viabilizada enquanto forma expressão do nativo no mundo e como linguagem carregada de símbolos. O etnomusicólogo então, em seu papel também de etnógrafo deve 'inscrever' o discurso social que permeia a prática discursiva. Para Geertz (1978) o objetivo não é a fala em si ou o acontecimento como acontecimento que o etnógrafo deve captar, mas sim o objetivo do discurso, seu 'noema' (seu pensamento, seu conteúdo e sua substância) ou mesmo o significado do acontecimento.

Quando pensamos a etnomusicologia, isso se dá por meio do objetivo de se tentar inscrever o que os informantes podem nos levar a compreender, através da busca por uma familiaridade com os nativos por meio "da adoção de uma perspectiva de dentro da sociedade" (PINTO, 2001, p. 244), buscando as causas, efeitos e processos mentais que carregam a produção da musicalidade nativa. Mas nisso acabamos por recair no problema da busca equivalente a uma abstração como o próprio termo 'música'. Mas se formos mais longe acabaremos nos deparando com uma série de outras terminologias que fazem parte desse mesmo campo amplo, tais como "ritmo, tonalidade, melodia, cantiga, instrumento, e mesmo de harmonia, compasso, cadência, escala, sonoridade, timbre, etc.” (PINTO, 2001, p. 245).

O trabalho de Bastos sobre A musicologia Kamayurá apresenta novos direcionamentos sobre a questão por desvendar, conforme Pinto (Ibid., p. 268), a noção de som (ihu) e de subcategorias sonoras e musicais, tais como ne'eng (a língua e a fala), kewere (a reza) e maraka (a música), sendo que maraka também pode significar o ato de fazer música como cantar, soprar, bater, rodar e chacoalhar. Outros casos apresentados por Pinto (2001, p. 242 e 245-246) também são igualmente relevantes para demonstrar algumas outras concepções locais acerca da música, tais como as músicas de pífanos e da gaita dos grupos de caboclos de Pernambuco e da Paraíba estudados por ele em 1984 e 1985, onde ele se deparou com uma afinação de 'terça neutra' tidas na Música Ocidental como algo 'fora do tom' ou 'desafinado', ou mesmo o caso da tradição da viola de samba do Recôncavo Baiano, o machete, em que seus modos de tocar locais são baseados em cinco 'tons' diferentes, sendo eles ré-maior, dó-maior, lá-maior, solmaior e mi-maior, mas que esta terminologia foge não só da concepção ocidental de música, como vai além dela mesmo que coincida com a relação tonal absoluta, estando relacionada a 
padrões acústico-emocionais, que caracterizam formas de tocar, como uma forma mais 'solta' e 'esparramada' em ré-maior, ou mesmo algo mais 'pesado' ou 'duro' em mi-maior.

Diferente de outras áreas do saber local, não é contraditório teorias nativas operarem no campo musical com concepções próprias, não-ocidentais, e utilizarem, ao mesmo tempo, esta terminologia, que é derivada da teoria musical europeia. Quando, no entanto, músicos, mestres e entendidos de manifestações de tradição local utilizam termos desta natureza, deparamos com uma ressignificação própria e precisa da terminologia, dentro de um corpo definido de saber (PINTO, 2001, p. 245).

O que está em jogo aqui é uma concepção no qual a cultura opera, segundo Sahlins (2003, p. 180-181), uma síntese entre estabilidade e mudança, onde mesmo a apropriação de conceitos e significados ocidentais estariam sujeitos a reavaliações práticas a nível local, em que a cultura local faz uso da cultura Ocidental (no qual tem contato) para seus próprios fins, mas de tal modo que mesmo que havendo transformação, isso acaba por resultar na sua reprodução cultural através da assimilação de um novo conteúdo empírico. É como demonstrado por Pinto (2001, p. 243) quando os músicos do Pernambuco e da Paraíba mesmo possuindo uma afinação específica característica de sua paisagem sonora regida pela 'terça neutra', continuam numa convivência pacífica com instrumentos como o acordeom, "com seus intervalos diatônicos temperados", representando a adaptação e a ressignificação promovida pela contato entre o que se tem pela cultura musical local e cultura musical ocidental, o que "denota a abertura com que estruturas tradicionais da sociedade no Nordeste abarcam elementos da globalização, sem por isso destruir ou renegar os conceitos próprios mais genuínos".

Em outro caso, Bastos (2014, p. 87) em nota de rodapé apresenta que quando se deu a popularização da música eclesiástica, expressão da visão de mundo religiosa dominante no período da Idade Média, foram estabelecidas igualmente relações de troca da mesma feita, na medida em que "A colonização musical, portanto - e não somente com relação a este primeiro kathólon Ocidental -, encontra na "profanização" o ato supremo de seu canibalismo". Continua ele que o exemplo dos casos de Portugal e Espanha são relevantes no tocante a esse ponto, dado que a imposição do Gregoriano, enquanto expressão da cultura dominante, foi carregada de dificuldades "devido a resistências heréticas muito disseminadas, a cantos 'católicos' locais como o da liturgia hispano-gótica - e à impregnação da Península pela colonização árabe”.

É dessa forma, que numa mesma direção se estabelece o posicionamento tomado por Sahlins, quando em Cosmologias do Capitalismo, se coloca contra a ideia de que a sociedade Ocidental ou o sistema mundial acabou por tomar "os povos colonizados e 'periféricos' em objetos passivos de sua própria história" (SAHLINS, 2004, p. 444). Essa atitude, que ele 
denomina de pessimismo sentimental, parte da ideia de que as culturas periféricas perderiam aspectos de suas respectivas culturas locais com o avanço do sistema mundial, e para ele não só não tem lugar em sua teoria como ele mesmo é da tese de que o sistema global atual é moldado também pelas culturas periféricas por meio de relações e trocas recíprocas entre o âmbito global e o âmbito local permeados num processo de choque entre ambas cosmologias que resultaria em assimilações, destruições e ressignificações possibilitando a formação de uma nova configuração.

Nesse ponto, se para Pinto (2001, p. 228-229) performance é entendida como um tipo de comportamento e maneira de viver experiências que não se limitam a cerimônias, rituais ou mesmo a eventos musicais e teatrais, mas que se estendem a todos os campos da vida, sendo um fenômeno que a tudo expressa e a tudo abarca, a performance musical, enquanto ritual, atua nesse processo de assimilação e ressignificação como um agente de conservação e de alteração de tradições e, portanto, dos significados coletivos.

\section{Considerações finais}

A genealogia da etnomusicologia traçada por Rafael José de Menezes Bastos e por Tiago de Oliveira Pinto parte das primeiras preocupações com o registro das manifestações musicais dos povos primitivos, dado o medo de que as suas práticas culturais fossem extintas, passando pelo estudo musicológico comparativo das manifestações da musicalidade dos diferentes povos e nações do mundo e pelo reconhecimento da música folclórica enquanto manifestação semelhante às músicas exóticas e primitivas. O percurso continua na Escola de Berlim de Musicologia Comparativa, ainda dominada pelas ideias difusionistas e evolucionistas predominantes na época, até a Sociedade Americana para Musicologia Comparativa de forte influência da etnologia de Boas na conformação dos objetivos da etnomusicologia enquanto área de pesquisa. Finalmente com Merriam, quadro da tradição de etnomusicologia norteamericana, houve a reformulação dos objetivos da disciplina.

A etnomusicologia passou por um longo trajeto que acabou por reforçar as distinções entre a construção de uma identidade baseada numa lógica de diferenciação entre um 'nós' e um 'outro'. Ela também se calcava numa visão metodológica que separando as abordagens musicológicas e antropológicas em duas formas de entendimento da música (o som enquanto fenômeno acústico e o comportamento, enquanto contexto cultural que permeia a prática musical) acabava por retirar o seu conteúdo semântico. A música se caracterizava, então, como um fenômeno do reino da sensibilidade e, portanto, incapaz de carregar sentido, significado e 
inteligibilidade. Na mesma direção se constituía um olhar atribuído aos nativos como vítimas do sistema global, na medida em que os primeiros intentos em registrar suas músicas tradicionais se davam pelo receio de sua extinção, isso acabava por retirar-lhes toda sua capacidade de agência, colocando-os como figuras passivas incapazes de participar em dinâmicas de trocas recíprocas, negando-lhes a capacidade de comunicar significados ou mesmo sentido por meio de suas práticas.

O trajeto iniciado por Merriam na tentativa de integrar as metodologias musicológicas e antropológicas permitiu um novo olhar sobre a disciplina, ao se apresentar como uma solução para o problema de inviabilização da música enquanto forma de linguagem carregada de significado e inteligibilidade, atribuindo aos estudos etnomusicológicos uma nova abordagem ao levar em conta o que o nativo tem a dizer sobre suas próprias construções simbólicas e suas práticas.

\section{REFERÊNCIAS}

BASTOS, Rafael Menezes. Esboço de uma Teoria da Música: Para além de uma Antropologia sem Música e de uma Musicologia sem Homem. ACENO, v. 1, n. 1, p. 49-101, jan./jul. 2014.

BOURDIEU, Pierre. A Distinção: uma crítica social do julgamento. São Paulo: Edusp; Porto Alegre, RS: Zouk, 2007.

GEERTZ, Clifford. Uma descrição densa: Por uma Teoria Interpretativa da Cultura. In: GEERTZ, Clifford. A Interpretação das Culturas. Rio de Janeiro: Zahar Editores, 1978.

PINTO, Tiago de Oliveira. Som e música. Questões de uma Antropologia Sonora. Revista de Antropologia, São Paulo, USP, v. 44, no 1, 2001.

SAHLINS, Marshall. Ilhas de História. Rio de Janeiro: Jorge Zahar Ed., 2003.

SAHLINS, Marshall. Cosmologias do Capitalismo. In: SAHLINS, Marshall. Cultura na Prática. Rio de Janeiro: Ed. UFRJ, 2004.

\section{Como referenciar este artigo}

SILVA, Jonathan Lambert. A etnomusicologia sob um olhar contemporâneo. Rev. Sem Aspas, Araraquara, v. 7, n. 2, p. 302-311, jul./dez., 2018. E-ISSN: 2358-4238. DOI: 10.29373/sas.v7i2.12498

Submetido em: $18 / 01 / 2019$

Aprovado em: 10/03/2019 